\title{
JNPH
}

Volume 6 No. 1 (April 2018)

(C) The Author(s) 2018

\section{PENGETAHUAN DAN SIKAP IBU YANG MEMILIKI BALITA DALAM PEMBERIAN OBAT PENURUN PANAS DI WILAYAH KERJA PUSKESMAS BETUNGAN KOTA BENGKULU}

\author{
KNOWLEDGE AND ATTITUDES OF MOTHERS WHOSE TODDLERS IN \\ DELIVERING FEVER MEDICATIONS IN BETUNGAN HEALTH \\ CENTER IN BENGKULU
}

\author{
YEYEN FITRI NINGSI \\ UPTD PUSKESMAS PERAWATAN BETUNGAN KOTA BENGKULU \\ JLN. DEPATI PAYUNG NEGARA KM 16,5 KELURAHAN BETUNGAN \\ KECAMATAN SELEBAR KOTA BENGKULU. 38214 \\ Email: yeyenfitria87@gmail.com/081368289824
}

\begin{abstract}
ABSTRAK
Demam pada anak-anak adalah salah satu kasus yang tidak dapat diabaikan. Berdasarkan data dari pusat kesehatan dari Januari hingga September 2016 ada 211 anak demam dengan sakit panas. Salah satu pengobatan demam adalah memberikan obat penurun demam, yang memiliki efek antipiretik. Dalam hal ini, tentu saja pengetahuan dan sikap ibu tentang pemberian obat demam untuk anak-anak sangat penting, karena dampak yang dapat ditimbulkan jika demam tidak ditangani akan menyebabkan kerusakan otak, hiperpireksia yang akan menyebabkan syok, epilepsi, keterbelakangan mental atau ketidakmampuan belajar bahkan dapat membahayakan keselamatan hidup. Penelitian ini untuk mengetahui hubungan dan sikap ibu yang memiliki anak dalam memberikan obat demam di Puskesmas Betungan. Penelitian ini merupakan penelitian analitik dengan menggunakan desain cross-sectional. Populasi penelitian adalah ibu yang memiliki anak dengan riwayat demam 3 bulan terakhir di Puskesmas Betungan, dengan ukuran sampel 68 orang, menggunakan teknik accidental sampling. Pengumpulan data dilakukan dengan wawancara langsung menggunakan kuesioner. Data dianalisis menggunakan analisis univariat dan bivariat dengan uji chi-square pada $\alpha 5 \%$. Hasil penelitian menunjukkan bahwa hampir separuh responden $(36,8 \%)$ memiliki pengetahuan yang kurang tentang obat untuk demam, hampir separuh responden (48,5\%) memiliki sikap yang kurang baik dalam pemberian obat penurun panas, dan hampir separuh responden $(26,5 \%)$ yang batita yang tidak diberi obat demam. Ada hubungan antara pengetahuan ibu yang memiliki anak dalam pemberian obat untuk demam Puskesmas Betungan Kota Bengkulu $(\rho=0,001)$, dan ada korelasi antara sikap ibu yang memiliki anak dalam pemberian obat untuk demam di Puskesmas Betungan Kota Bengkulu $2016(\rho=0,009)$. Diharapkan Puskesmas Betungan lebih intensif untuk memberikan penyuluhan dan promosi kesehatan serta penyediaan obat penurun demam, seperti di Pusat Kesehatan Terpadu, di program desa, serta menyediakan selebaran / brosur tentang pemberian obat demam dengan tepat.
\end{abstract}

Kata kunci: Pengetahuan, Sikap, dan Obat Demam 


\begin{abstract}
Fever on children is one of those cases that cannot be ignored. Based on data from a health center from January to September 2016 there were 211 febrile children with fever. One of fever treatment is to give fever-reducing medicine, which has antipyretic effect. In this case, of course knowledge and attitudes of mothers about delivering fever medications to children is very important, because of the impact that can be caused if the fever is not handled will cause brain damage, hyperpyrexia which would cause shock, epilepsy, mental retardation or learning disabilities can even endanger the safety of life.This study was to determine the relationship and attitude of mothers who have children in delivering fever medication in Betungan health center in the city.This study was an analytical study using cross-sectional design. The study population were mothers who have children with a history of fever last 3 months in Betungan health center, with the sample size of 68 people, using accidental sampling technique. Data collection was done by direct interview using a questionnaire. Data were analyzed using univariate and bivariate analysis with chi-square test at $\alpha 5 \%$.The results showed that almost half of respondents $(36.8 \%)$ had less knowledge about medication for fever, almost half of respondents (48.5\%) had unfavorable attitude in granting febrifuge, and almost half of respondents $(26.5 \%)$ whose toddlers who were not given medicine for fever. There was a relationship between knowledge of mothers who have children in drug delivery for fever in Betungan health center in Bengkulu City $(\rho=0.001)$, and there was a correlation between the attitudes of mothers who have children in drug delivery for fever in Betungan health center in Bengkulu City 2016 ( $\rho=$ 0.009).It is expected that Betungan health center to be more intensive to provide counseling and health promotion and provision of febrile febrifuge, such as in The Integrated Health Center, at village programs, as well as providing leaflets / brochures on granting fever medications appropriately.
\end{abstract}

Keywords: Knowledge, Attitudes, and Fever Medication

\section{PENDAHULUAN}

Menurut Kaneshiro \& Zieve, dalam Dwijaya (2011), demam adalah peninggian suhu tubuh dari variasi suhu normal seharihari yang berhubungan dengan peningkatan titik patokan suhu di hipotalamus. Demam terjadi pada oral temperature $>37,2^{\circ} \mathrm{C}$.

Salah satu penanganan demam yaitu dengan memberikan obat-obatan. Salah satu diantara obat yang dapat mengatasi demam adalah parasetamol (Dermawan, 2014).

Perlakuan dan penanganan yang salah, lambat, dan tidak tepat akan mengakibatkan terganggunya pertumbuhan dan perkembangan tubuh balita, bahkan dapat membahayakan keselamatan jiwanya. Karena itu pengetahuan yang lengkap berkaitan dengan demam pada balita wajib dikuasai dengan baik oleh para orang tua khususnya ibu. Dengan begitu bukan kepanikan yang muncul ketika buah hatinya mengalami demam, melainkan sikap yang tepat dan tindakan atau pertolongan pertama yang segera dilakukan untuk mencegah akibat yang lebih buruk (Widjaja, 2011).

Berdasarkan data Dinkes Kota Bengkulu 2014 cakupan pelayanan MTBS pada anak balita sakit menunjukan bahwa kunjungan tertinggi pertama yaitu di Wilayah Kerja Puskesmas Betungan sebanyak 3.254 balita, yang kedua di Wilayah Kerja Puskesmas Nusa Indah sebanyak 1.934 balita dan yang ketiga di Wilayah Kerja puskesmas Pasar Ikan sebanyak 1.794 balita. Berdasarkan data Puskesmas Betungan data kunjungan balita dari bulan JanuariSeptember 2015 yaitu sebanyak 3.231 balita dan data balita yang menderita febris sebanyak 211 orang.

Berdasarkan survey awal berupa wawancara dari ibu yang mempunyai anak balita di Wilayah Kerja Puskesmas Betungan didapatkan gambaran mengenai pengetahuan 
dan sikap ibu. Dari 10 orang ibu yang balitanya mengalami demam, 7 orang diwawancarai kurang mengetahui konsep pemberian obat penurun panas yaitu parasetamol atau ibuprofen, dan efek samping akibat dari minum obat penurun panas tersebut, dan 3 orang mengatakan bahwa mengetahui konsep demam dan efek samping pemberian obat sehingga kalau balitanya mengalami demam suhu tubuhnya belum terlalu tinggi maka ibu mengatasinya dengan memberikan minum air putih yang banyak semampu anaknya minum antara 6-8 gelas dalam 24 jam, dikompres hangat dan istirahat yang cukup. Apabila balitanya demamnya semakin tinggi baru ibu memberikan obat penurun panas dan segera di bawa ke tempat pelayanan kesehatan terdekat. Hal ini menggambarkan bahwa pengetahuan ibu masih kurang. Sedangkan sikap ibu dari hasil 7 orang diwawancara tersebut yaitu; Ibu mengatakan bahwa jika balitanya demam harus segera diberikan obat penurun panas, balita yang mulai demam harus segera dibawa ke dokter, balita demam harus istirahat penuh. Hal tersebut menunjukkan sikap yang ibu miliki untuk memberikan perawatan pada balita demam masih kurang.

Berdasarkan latar belakang diatas, maka peneliti tertarik untuk melakukan penelitian tentang "Hubungan pengetahuan dan sikap ibu yang memiliki balita dalam pemberian obat penurun panas di Wilayah Kerja Puskesmas Betungan Kota Bengkulu.

\section{BAHAN DAN METODE}

Teknik pengumpulan data yang digunakan dalam penelitian ini adalah dengan menggunakan data primer dan data sekunder. Data primer adalah data yang dikumpulkan melalui penyebaran kuesioner langsung pada responden di wilayah kerja puskesmas Betungan kota Bengkulu. Sedangkan data sekunder adalah data yang diperoleh dari laporan tahunan dinas kesehatan kota Bengkulu dan buku register poli balita puskesmas Betungan kota Bengkulu tahun 2015. Uji statistik menggunakan uji Chi-
Square dengan tingkat kepercayaan $95 \% \alpha=$ 0,05

Penelitian ini menggunakan rancangan penelitian cross sectional. Populasi dalam penelitian ini seluruh ibu yang memiliki balita yang berobat ke Puskesmas Betungan karena mengalami demam (febris) periode Januari sampai September 2015 yang berjumlah 211 orang. Teknik pengambilan sampel dengan accidental sampling.

\section{HASIL PENELITIAN}

Wilayah Kerja Puskesmas Betungan mempunyai program unggulan yaitu Promkes (berupa penyuluhan langsung ke masyarakat, penyebaran info sehat, dan majalah dinding), Kesehatan Ibu dan Anak (KIA) termasuk Keluarga Berencana (KB) dan imunisasi (berupa pemeriksaan ibu hamil, pemantauan tumbuh kembang anak, konseling, pelayanan dan pemasangan alat kontrasepsi serta posyandu), kesehatan lingkungan, peningkatan gizi, Pemberantasan Penyakit Menular (P2M), dan pengobatan (Profil Puskesmas Betungan, 2016).

Data yang diperoleh dari penelitian kemudian dikelompokan dan ditabulasi sesuai dengan keperluan peneliti. Selanjutnya peneliti melakukan pengolahan data dan analisis data. Hasil penelitian disajikan dalam analisis univariat dari setiap variabel independen dan dependen.penyajian dilanjutkan dengan hasil analisis bivariat yang bertujuan untuk mengetahui hubungan antara variabel independen dengan variabel dependen. Dengan hasil penelitian sebagai berikut:

\section{Tabel 1 Distribusi Frekuensi Pengetahuan Ibu dalam Pemberian Obat Penurun Panas Di Wilayah Kerja Puskesmas Betungan Kota Bengkulu}

\begin{tabular}{ccc}
\hline Pengetahuan Ibu & Frekuensi & Persentase (\%) \\
\hline Kurang & 25 & 36,8 \\
Cukup & 26 & 38,2 \\
Baik & 17 & 25,0 \\
\hline Total & 68 & 100,0 \\
\hline
\end{tabular}


Berdasarkan tabel 1 di atas dapat diketahui bahwa hampir sebagian responden $(38,2 \%)$ memiliki pengetahuan cukup tentang pemberian obat penurun panas.

Tabel 2 Distribusi Frekuensi Sikap Ibu dalam Pemberian Obat Penurun Panas Di Wilayah Kerja Puskesmas Betungan Kota Bengkulu

\begin{tabular}{ccc}
\hline Sikap Ibu & Frekuensi & Persentase (\%) \\
\hline Unfavorabel & 33 & 48,5 \\
Favorabel & 35 & 51,5 \\
\hline Total & 68 & 100,0 \\
\hline
\end{tabular}

Berdasarkan tabel 2 di atas dapat diketahui bahwa sebagian besar responden $(51,5 \%)$ memiliki sikap favorabel dalam pemberian obat penurun panas.

Tabel 3 Distribusi Frekuensi Pemberian Obat Penurun Panas Di Wilayah Kerja Puskesmas Betungan Kota Bengkulu

\begin{tabular}{ccc}
\hline $\begin{array}{c}\text { Pemberian Obat } \\
\text { Penurun Panas }\end{array}$ & Frekuensi & Persentase (\%) \\
\hline Tidak diberikan & 18 & 26,5 \\
Diberikan & 50 & 73,5 \\
\hline Total & 68 & 100,0 \\
\hline
\end{tabular}

Berdasarkan tabel 3 di atas dapat diketahui bahwa sebagian besar responden $(73,5 \%)$ balitanya febris diberikan obat penurun panas.

Tabel 4 Hubungan Pengetahuan Ibu dalam Pemberian Obat Penurun Panas Di Wilayah Kerja Puskesmas Betungan Kota Bengkulu

\begin{tabular}{|c|c|c|c|c|c|c|c|}
\hline \multirow{3}{*}{$\begin{array}{c}\text { Pengetahuan } \\
\text { Ibu }\end{array}$} & \multicolumn{6}{|c|}{ Pemberian Obat Penurun Panas } & \multirow{3}{*}{$\rho$} \\
\hline & \multicolumn{2}{|c|}{$\begin{array}{c}\text { Tidak } \\
\text { diberikan }\end{array}$} & \multicolumn{2}{|c|}{$\begin{array}{c}\text { Diberika } \\
\mathrm{n}\end{array}$} & \multicolumn{2}{|c|}{ Total } & \\
\hline & $\mathrm{N}$ & $\%$ & $\mathrm{n}$ & $\%$ & & $\%$ & \\
\hline Kurang & 13 & 52,0 & 12 & 48,0 & 25 & 100 & \\
\hline Cukup & 3 & 11,5 & 23 & 88,5 & 26 & 100 & 0,001 \\
\hline Baik & 2 & 11,8 & 15 & 88,2 & 17 & 100 & \\
\hline Total & 18 & 26,5 & 50 & 73,5 & 68 & 100 & \\
\hline
\end{tabular}

Berdasarkan tabel 4 diatas diketahui bahwa dari 25 responden yang memiliki pengetahuan kurang terdapat sebagian besar responden $(52,0 \%)$ balitanya tidak diberikan obat penurun panas, dan hampir sebagian responden $(48,0 \%)$ balitanya diberikan obat penurun panas, dari 26 responden yang memiliki pengetahuan cukup terdapat hampir seluruh responden $(88,5 \%)$ balitanya diberikan obat penurun panas, dan sebagian kecil responden $(11,5 \%)$ balitanya tidak diberikan obat penurun panas,dan dari 17 responden yang memiliki pengetahuan baik terdapat hampir seluruh responden $(88,2 \%)$ balitanya diberikan obat penurun panas dan sebagian kecil responden $(11,8 \%)$ balitanya tidak diberikan obat penurun panas. Berdasarkan hasil analisis uji Chi-Square (Pearson Chi-Square) didapat nilai $\rho=0,001$ $<\alpha 0,05$, yang berarti Ho ditolak dan $\mathrm{Ha}$ diterima, yang menunjukan bahwa ada hubungan yang bermakna antara pengetahuan ibu dalam pemberian obat penurun panas di Wilayah Kerja Puskesmas Betungan Kota Bengkulu Tahun 2016.

Tabel 5 Hubungan Sikap Ibu dalam Pemberian Obat Penurun Panas Di Wilayah Kerja Puskesmas Betungan Kota Bengkulu

\begin{tabular}{|c|c|c|c|c|c|c|c|}
\hline \multirow{3}{*}{ Sikap Ibu } & \multicolumn{6}{|c|}{ Pemberian Obat Penurun Panas } & \multirow{3}{*}{$\rho$} \\
\hline & \multicolumn{2}{|c|}{$\begin{array}{c}\text { Tidak } \\
\text { diberikan }\end{array}$} & \multicolumn{2}{|c|}{$\begin{array}{c}\text { Diberika } \\
n\end{array}$} & \multicolumn{2}{|c|}{ Total } & \\
\hline & $\mathrm{N}$ & $\%$ & $\mathrm{n}$ & $\%$ & $\mathrm{n}$ & $\%$ & \\
\hline Unfavorabel & 14 & 42,4 & 19 & 57,6 & 33 & 100 & \\
\hline Favorabel & 4 & 11,4 & 31 & 88,6 & 35 & 100 & 0,009 \\
\hline Total & 18 & 26,5 & 50 & 73,5 & 68 & 100 & \\
\hline
\end{tabular}

Berdasarkan tabel 5 diketahui bahwa dari 33 responden yang memiliki sikap Unfavorabel terdapat hampir sebagian responden $(42,2 \%)$ balitanya tidak diberikan obat penurun panas, dan sebagian besar responden $(57,6 \%)$ balitanya diberikan obat penurun panas, dan dari 35 responden yang memiliki sikap Favorabel, terdapat hampir seluruh responden $(88,6 \%)$ balitanya diberikan obat penurun panas dan sebagian 
kecil $(11,4 \%)$ balitanya tidak diberikan obat penurun panas . Berdasarkan hasil analisis uji Chi-Square (Continuity Correction) didapat nilai $\rho=0,009<\alpha 0,05$, yang berarti Ho ditolak dan Ha diterima, yang menunjukan bahwa ada hubungan yang bermakna antara sikap ibu dalam pemberian obat penurun panas di Wilayah Kerja Puskesmas Betungan Kota Bengkulu.

\section{PEMBAHASAN}

Berdasarkan hasil penelitian diketahui dari 68 responden yang dijadikan sampel terdapat hampir sebagian responden $(38,2 \%)$ memiliki pengetahuan cukup tentang pemberian obat penurun panas.Hasil penelitian ini didukung teori Notoatmodjo (2012), yang mengatakan sebagian besar pengetahuan manusia diperoleh melalui mata dan telinga. sebagian besar responden (51,5\%) mempunyai sikap favorabel dalam pemberian obat penurun panas.Hasil penelitian ini sejalan dengan teori Notoatmodjo, (2012) yang mengatakan sikap adalah evaluasi umum yang dibuat manusia terhadap dirinya sendiri, orang lain, objek. sebagian besar responden $(73,5 \%)$ balitanya febris diberikan obat penurun panas.Hasil penelitian ini didukung teori Rochimah (2011), yang mengatakan obat adalah suatu subtansi atau bahan yang di gunakan untuk mendiagnosa, menyembuhkan, mengatasi, membebaskan suatu penyakit untuk mendapatkan efek terafeutik namun bisa salah dapat mengakibatkan alergi dan shock bahkan kematian. Berdasarkan hasil analisis uji ChiSquare (Pearson Chi-Square) didapat nilai $\rho$ $=0,001<\alpha 0,05$, yang berarti Ho ditolak dan Ha diterima, yang menunjukan bahwa ada hubungan yang bermakna antara pengetahuan ibu dalam pemberian obat penurun panas pada balita Di Wilayah Kerja Puskesmas Betungan Kota Bengkulu. hasil analisis uji Chi-Square (Continuity Correction) didapat nilai $\rho=0,009<\alpha 0,05$, yang berarti Ho ditolak dan Ha diterima, yang menunjukan bahwa ada hubungan yang bermakna antara sikap ibu dalam pemberian obat penurun panas pada balita Di Wilayah Kerja Puskesmas Betungan Kota Bengkulu.

\section{KESIMPULAN}

Dari hasil penelitian yang telah dilakukan dapat disimpulkan sebagai berikut :

1. Hampir sebagian ibu balita di Wilayah Kerja Puskesmas Betungan Kota Bengkulu memiliki pengetahuan kurang dalam pemberian obat penurun panas.

2. Sebagian besar ibu balita di Wilayah Kerja Puskesmas Betungan Kota Bengkulu memiliki sikap favorabel dalam pemberian obat penurun panas.

3. Sebagian besar balita di Wilayah Kerja Puskesmas Betungan Kota Bengkulu diberikan obat penurun panas kalau mengalami febris.

4. Ada hubungan yang bermakna antara pengetahuan ibu yang memiliki balita dalam pemberian obat penurun panas di Wilayah Kerja Puskesmas Betungan Kota Bengkulu.

5. Ada hubungan yang bermakna antara sikap ibu yang memiliki balita dalam pemberian obat penurun panas di Wilayah Kerja Puskesmas Betungan Kota Bengkulu.

\section{SARAN}

Berdasarkan dari kesimpulan hasil penelitian yang telah dilakukan di Puskesmas Betungan Kota Bengkulu Tahun 2016, maka penulis menyarankan:

1. Bagi Dinas Kesehatan Kota Bengkulu

Pihak pemerintah dalam hal ini Dinas Kesehatan perlu menyusun program kegiatan untuk memberi edukasi atau penyuluhan yang dapat membantu meningkatkan pengetahuan ibu-ibu tentang pemberian obat penurun panas dan sikap dalam pemberian obat penurun panas, supaya dapat melakukan penanganan demam yang baik terhadap anak mereka sehingga dapat meningkatkan derajat kesehatan. 
2. Bagi pihak Puskesmas

Disarankan agar petugas kesehatan di Puskesmas Betungan lebih intensif memberikan konseling dan promosi kesehatan tentang febris dan pemberian obat penurun panas, baik di posyandu, poskades, pertemuan PKK, dan menyediakan leaflet/brosur tentang pemberian obat penurun panas dan febris.

\section{Akademik}

Penelitian ini diharapkan dapat menjadi sebagai sumber pengetahuan tentang pemberian obat penurun panas, sehingga peneliti selanjutnya tidaK mengalami kesulitan untuk mencari referensi.

\section{Peneliti Selanjutnya}

Bagi peneliti selanjutnya disarankan agar dapat menyempurnakan penelitian ini dengan metode yang lebih lengkap diantaranya pengumpulan data tidak hanya menggunakan kuesioner tetapi diikuti dengan observasi, serta wawancara yang mendalam sehingga didapatkan hasil yang lebih baik, dan meneliti variabel lain seperti tingkat pendidikan, lingkungan, tingkat sosial ekonomi.

\section{DAFTAR PUSTAKA}

Dermawan. 2014. Farmakologi untuk Keperawatan. Yogyakarta : Gosyen Publishing

Dwijaya. 2011. Gambaran Pengetahuan, Sikap, dan Tindakan Ibu dalam Pemberian Parasetamol kepada Anak sebagai Penatalaksanaan Awal Demam di Kelurahan Tegal Sari Mandala Kecamatan II Denai Medan. http://skripsieceran.blogspot.co.id/2014/ 12/download-skripsi-kedokteran.

Mei.2012. hubungan pengetahuan dan sikap orang tua terhadap perilaku orang tua dalam pemberian obat penurun panas (Antiperetik) pada anak usia infant (0-1 tahun). (diakses 25 juni 2016) di unduh dari schoola google. Co.id
Notoatmodjo. 2012. Metodologi Penelitian Kesehatan. Jakarta : Rineka Cipta. 2012. Promosi Kesehatan dan Perilaku Kesehatan. Jakarta : Rineka Cipta.

Profil Dinas Kesehatan Kota Bengkulu. 2015. Profil Kesehatan Kota Bengkulu Tahun 2014. Bengkulu.

Profil Puskesmas Betungan Kota Bengkulu. 2015. Profil Puskesmas Betungan Kota Bengkulu Tahun 2015. Bengkulu.

Rochimah, dkk. 2011. Keterampilan Dasar Praktik Klinik (KPDK). Jakarta : Trans Info Media. 